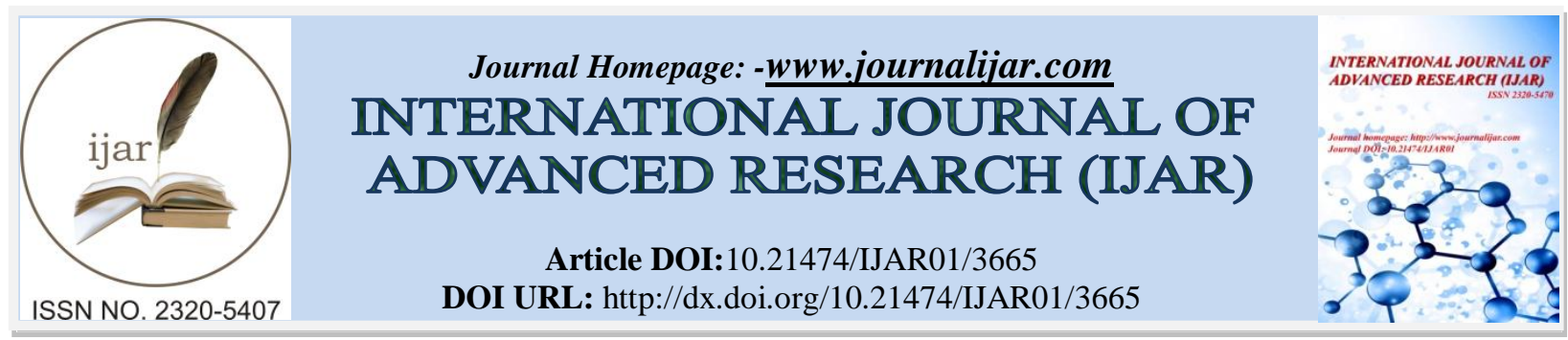

RESEARCH ARTICLE

\title{
EFFECT OF IMPELLER ROTATIONAL SPEED ON FLOW BEHAVIOR IN FULLY BAFFLED MIXING TANK.
}

\author{
Adnan A. Abdul rasool ${ }^{1}$, Safaa S. Ahmad ${ }^{1}$ and F. A. Hamad ${ }^{2}$. \\ 1. A: mech. Eng. Dept, college of engineering, al-mustansiriya university, Baghdad, Iraq. \\ 2. B: school of science \& engineering, teesside university, middlesbrough, Ts1 3ba, U.K.
}

\section{Manuscript Info}

Manuscript History

Received: 11 January 2017

Final Accepted: 02 February 2017

Published: March 2017

Key words:-

fluid flow in mixing tank, mixing,

Retreat Curve impeller

\section{Abstract}

This paper reports the results of numerical study undertaken to investigate the effect of impeller rotational speed on velocity field in mixing tank. The hydrodynamic of the flow in standard mixing tank generated by retreat curve 3-blaed impellers, (radial flow) is studied. Using ANSYS FLUENT v15.4.to solve the continuity and momentum equations incorporating the RNG K- $\varepsilon$ turbulence model with the standard wall function available in Fluent. The multiple frames of reference (MFR) model is used for impeller modeling. The results show that the velocity fluctuated increased with the rotational speed.

Copy Right, IJAR, 2017,. All rights reserved.

\section{Introduction:-}

Mixing tanks is one of the techniques that is widely used and play a significant role in industrial processes to homogenize the mixture of two or more fluids/solids by using rotating impeller. The better understanding of the fluids behavior in mixing vessel may improve the performance of impeller and the mixing process. Means e.g. the main aims of using missing is to improve the mass and heat transfer and to generate a homogenized mixture to minimize the settling of the particles at the bottom of the tank. A summary of some recent published works in the literature is given below.

(Wei et al 1997) [1] Studied the influence of the number and width of baffles in mechanically mixing vessel with and without aeration on the fluid hydrodynamics and mixing tank. (Ducoste and Clark 1999) [2] Employed the Computational Fluid Dynamics (FIDAP) code called Fluid Dynamics International, Evanston, IL in the study. The model was a simple geometry consists of the submerged impellers in cubical mixing vessel. The k- $\varepsilon$ model was used to simulate the turbulence and the flow pattern induced in the vessel. (Masoud Rahimi 2005) [3] Used CFD simulation to study the influence of impellers number and layout on mixing time. A large storage tank of 19000m3 contain three types of crude oil with difference density. (Aoyi et al 2008) [4] Investigated the hydrodynamics of fluid in mixing stirred vessel agitated by Rushton turbine with low clearance condition. The CFD technique and LDV measurements were performed in order to understand the flow pattern and estimated the mixing time. (Angelique Delafosse et. al. 2008) [5] Investigated the hydrodynamics in mixing tank by CFD simulation. Two models were used to determine the dissipation rate and its distribution in mixing vessel. Three dimensional simulations using the commercial CFD code FLENT 6.2.16 based on the Unsteady Reynolds Averaged NaiverStokes equations (URANS) model and Large Eddy simulation (LES) model was used (Zadghaffari et. al. 2008)[6] Studied the flow field, power and mixing time in mixing tank agitated by a double Rushton turbine. It was observed that a considerable reduction in mixing time can be achieved by increasing impeller rotation speed and reasonable agreement between the simulation and experimental results were obtained. The comparisons pointed the advantages 
of this CFD approach as a computational tool for designing mixing reactors. (Ameur and Bouzit 2012) [7] Studied the effect of blades number on mixing performance in shear thinning fluid. The simulations and calculations of impeller were performed using computer code (CFX11.0). It has been shown that the axial velocity is directly proportional to Reynolds number which results an increasing in cavern size. The maximum values of tangential velocity are located at the tip of blade for any number of blades. The tangential velocity degradation is greater with impeller have two blades when compared with the other cases, while the difference becomes insignificant between an impeller with six and eight blade. (Meriem Ammar et. al. 2012) [8] Studied the effect of tank design on the flow pattern. Three baffles less stirred vessel types have been prepared, cylindrical, curved, and spherical vessel. It has been mentioned that the curved bottom tank reduced the low velocity flow zones, and established more uniformity for entirely tank volume. By the comparison between LDV data and simulation results, it can be consider that the CFD code is valid for predicting the fluid hydrodynamics in mixing vessel. (Sharma and Genitha 2014) [9] Numerically investigated the effect of different impellers on aerobic baffles stirred tank fermenter. The performance of aerobic stirred tank fermenter evolution was performed by using various software packages, Autodesk simulation CFD, and ANSYIS FLUENT. The k- $\varepsilon$ model, k- $\omega$ model, Shear Stress Transport (SST) model and Scale Adaptive Simulation (SAS) model were used to represent the turbulence. It has been observed that the axial flow component for all impellers was restrained on the bottom of the tank; consequently the overall flow was mainly radial. This will weak the axial velocity distribution at the bottom of mixing vessel, therefore the solid particles stays around the bottom of the tank. The 6-blade Rushton turbine equipped with walled baffles induced the best state for mass transfer. (Arturo J. et. al. 2015)[10] Examined the optimal location of one or two axial impellers on central shaft in tall stirred tank through establishing a connection of Evolutionary Program EP and CFD technique. It has been noted the optimum mixing time and power consumption can be achieved through the utilization of EP method. For mixing process established with one impeller the optimum mixing performed at clearance $\mathrm{C}=0.13418 \mathrm{~m}$ and for two impellers system it's achieved with clearance $C=0.26441$ and impeller space $h=0.1601 \mathrm{~m}$. The evolution process selected the best entities according to operation condition for realizing optimum conditions.

In this paper, the flow field in stirred tank is studied using ANSYS Fluent v15.4 to identify the dead zones in the tank where the fluid is not mixing by presenting the velocity vectors at different planes in the tank. This will give better information which improves tank design in accordance with operation conditions.

\section{Theoretical Analysis:-}

\section{CFD Model and Simulation:-}

A schematic diagram of the tank and the impeller is shown in Figure 1. The system consists of a flat bottomed cylindrical vessel, the vessel diameter $(\mathrm{Dt}=0.3 \mathrm{~m}$ ) of which equals the height of the liquid $(\mathrm{H}=\mathrm{Dt})$. Four baffles having width, $\mathrm{W}=\mathrm{Dt} / 10$ are spaced equally around the vessel. The shaft of the impeller is concentric with the axis of the vessel. The impeller diameter, Di, equivalent to $\mathrm{Dt} / 3$. And the blead radius $0.3 \mathrm{~m}$ and blead height is $.03 \mathrm{~m}$ The distance between the tank bottom and the impeller position $\mathrm{C}$ is set to $\mathrm{C}=\mathrm{Dt} / 3$. The rotational speed of the impeller, $\mathrm{N}$, is ranging from $60 \mathrm{rpm}$ to $135 \mathrm{rpm}$ increasing step $15 \mathrm{rpm}$, leading to a tip speed, Vtip, ranging $0.314 \mathrm{~m} / \mathrm{s}$ to 1.05 $\mathrm{m} / \mathrm{s}$. The working fluid is water with density, $\rho$, of $1000 \mathrm{~kg} / \mathrm{m} 3$ and viscosity, $\mu$, of $1 \times 10-3$ Pa.s. The mixing tank was design depending on the standard configuration [11], (Georgy 1991)[12]. The retreat impeller showed in Figure 2 .

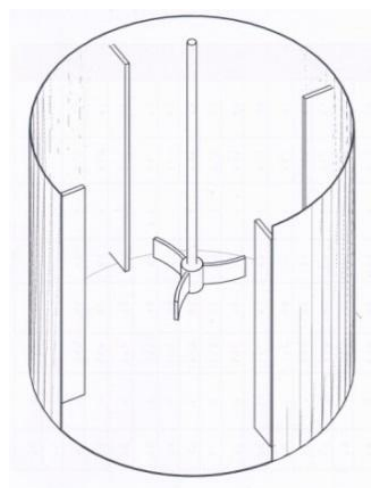

Figure1:- mixing Tank in Present Study 


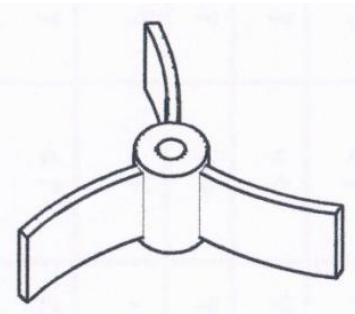

Figure 2:- Retreat impellerGeometry.

\section{Governing equations:-}

\section{Continuity equation:-}

The net flow of mass across the boundary of a control volume is zero in steady state flow:

$\nabla \cdot \breve{G}=0$

Where:

$\breve{G}=\rho \bar{V}$, is mass velocity.

Equation (1) can be written relative to cylindrical coordinates as follows:

$$
\frac{\partial G_{z}}{\partial z}+\frac{1}{r} \frac{\partial}{\partial r}\left(r G_{r}\right)+\frac{1}{r} \frac{\partial G_{\theta}}{\partial \theta}=0
$$

The subscripts $\mathrm{z}, \mathrm{r}$ and $\Theta$ are representing to the axial, radial and tangential components respectively. The $\bar{u}$, $\bar{v}$ and $\bar{w}$ are the components for the time mean velocity in $\mathrm{z}, \mathrm{r}$ and $\Theta$ directions respectively, and $\mathrm{u}^{\prime}, \mathrm{v}^{\prime}$ and $\mathrm{w}^{\prime}$ be the corresponding velocities of fluctuation. The continuity equation can be written as conservation of mass equation with the following form :( Joseph 1997), (Ronald 1984)

$$
\frac{\partial}{\partial z}(\bar{u})+\frac{1}{r} \frac{\partial}{\partial r}(r \bar{v})+\frac{1}{r} \frac{\partial}{\partial \theta}(\bar{w})=0
$$

\section{Momentum Equation:-}

The general momentum equations in terms of shear stress $\tau$ governing the fluid motion for three dimensions for cylindrical coordinate are [9]:

\section{In Z-direction}

$$
\rho\left(\frac{\partial U}{\partial t}+U \frac{\partial U}{\partial z}+V \frac{\partial U}{\partial r}+\frac{W}{r} \frac{\partial U}{\partial \theta}\right)=-\frac{\partial p}{\partial z}+\left[\frac{1}{r} \frac{\partial}{\partial r}\left(r \tau_{r z}\right)+\frac{1}{r} \frac{\partial}{\partial \theta} \tau_{\theta z}+\frac{\partial}{\partial z} \tau_{z z}\right]+\rho F z
$$

\section{In R-direction}

$$
\rho\left(\frac{\partial V}{\partial t}+U \frac{\partial V}{\partial z}+V \frac{\partial V}{\partial r}+\frac{W}{r} \frac{\partial V}{\partial \theta}-\frac{W^{2}}{r}\right)=-\frac{\partial p}{\partial r}+\left[\frac{1}{r} \frac{\partial}{\partial r}\left(r \tau_{r r}\right)+\frac{1}{r} \frac{\partial}{\partial \theta} \tau_{\theta r}+\frac{\partial}{\partial z} \tau_{z r}-\frac{{ }^{\tau} \theta \theta}{r}\right]+\rho F r
$$

\section{In- $\theta$-direction}

$\rho\left(\frac{\partial W}{\partial t}+V \frac{\partial W}{\partial r}+\frac{W}{r} \frac{\partial W}{\partial \theta}+\frac{W V}{r}+U \frac{\partial W}{\partial z}\right)=-\frac{1}{r} \frac{\partial p}{\partial \theta}+\left[\frac{1}{r^{2}} \frac{\partial}{\partial r}\left(r^{2} \tau\right)+\frac{1}{r} \frac{\partial}{\partial \theta} \tau \theta \theta+\frac{\partial}{\partial z} \tau_{z \theta}+\frac{{ }^{\tau} \theta r-\tau}{r} r \theta\right]+\rho F \theta$

The previous equations of mass conservation and momentum can be combined to formof one general form (Versteeg 1995)

$$
\frac{\partial \psi_{z}}{\partial z}+\frac{1}{r} \frac{\partial\left(r \psi_{r}\right)}{\partial r}+\frac{1}{r} \frac{\partial\left(r \psi_{\theta}\right)}{\partial \theta}=S_{\Phi}
$$

For the continuity and momentum the $\psi \mathrm{z}, \psi \mathrm{r}$, and $\psi \Theta$ are the total diffusion fluxes defined by:

$$
\begin{aligned}
& \psi_{z}=\rho U \phi-\Gamma_{\phi} \frac{\partial \phi}{\partial z} \\
& \psi_{r}=\rho V \phi-\Gamma_{\phi} \frac{\partial \phi}{\partial r}
\end{aligned}
$$


$\psi_{\theta}=\rho W \phi-\Gamma_{\phi} \frac{\partial \phi}{r \partial \theta}$

Where $\Phi$ stands for any of the dependent variables and the corresponding values of $\Gamma_{\phi}$ and $S_{\phi}$ is indicated in table (1).For axisymmetric swirling flow $\left(\frac{\partial \phi}{\partial \theta}=0\right)$, equation (7) becomes:

$$
\begin{aligned}
& \frac{\partial \psi_{z}}{\partial z}+\frac{1}{r} \frac{\partial\left(r \psi_{r}\right)}{\partial r}=S \\
& \rho \frac{\partial}{\partial z}\left(U \phi-\Gamma_{\phi} \frac{\partial \phi}{\partial z}\right)+\frac{1}{r} \frac{\partial}{\partial r}\left(r V \phi-r \Gamma_{\phi} \frac{\partial \phi}{\partial r}\right)=S_{\phi}
\end{aligned}
$$

\begin{tabular}{|c|c|c|c|c|c|}
\hline Equation & $\Phi$ & $\Gamma_{\Phi}$ & $S_{\Phi}$ & & \\
\hline Conservation of mass Eq(2) & 1 & 0 & 0 & & \\
\hline $\begin{array}{l}\text { Conservation of momentum in } z- \\
\text { direction eq. (4) }\end{array}$ & $U$ & $\mu_{e f f}$ & $-\frac{\partial \bar{p}}{\partial z}+\frac{\partial}{\partial z}\left(\mu_{e f f} \frac{\partial \bar{u}}{\partial z}\right)+\frac{1}{r} \frac{\partial}{\partial r}\left[r \mu_{e f f}\left(\frac{\partial \bar{v}}{\partial z}\right)\right]+\frac{1}{r} \frac{\partial}{\partial \theta}$ & {$\left[\mu_{e f f}\left(\frac{\partial \bar{w}}{\partial z}\right)\right]$} & \\
\hline $\begin{array}{l}\text { Conservation of momentum in } r- \\
\text { direction eq. (5) }\end{array}$ & $V$ & $\mu_{e f f}$ & $\begin{array}{l}-\frac{\partial \bar{p}}{\partial r}+\frac{\partial}{\partial z}\left[\mu_{e f f} \frac{\partial \bar{u}}{\partial r}\right]+\frac{1}{r} \frac{\partial}{\partial r}\left[r \mu_{e f f} \frac{\partial \bar{v}}{\partial r}\right]+\frac{1}{r} \frac{\partial}{\partial \theta}\left[\mu_{e f}\right. \\
\rho \frac{\bar{w}^{2}}{r}-\frac{2 \mu_{e f f}}{r}\left(\frac{1}{r} \frac{\partial \bar{w}}{\partial \theta}+\frac{\bar{v}}{r}\right)\end{array}$ & $\left(r \frac{\partial\left(\frac{\bar{w}}{r}\right)}{\partial r}\right.$ & \\
\hline $\begin{array}{l}\text { Conservation of momentum in } \theta \text { - } \\
\text { direction eq. (6) }\end{array}$ & $\boldsymbol{W}$ & $\mu_{e f f}$ & $\begin{array}{l}-\frac{1}{r} \frac{\partial \bar{p}}{\partial \theta}+\frac{\partial}{\partial z}\left[\mu_{e f f}\left(\frac{1}{r} \frac{\partial \bar{u}}{\partial \theta}\right)\right]+\frac{1}{r} \frac{\partial}{\partial r}\left[\mu_{e f f}\left(\frac{\partial \bar{v}}{\partial \theta}-\bar{w}\right)\right]+\frac{\mu_{e f f}}{r} \\
+\frac{1}{r} \frac{\partial}{\partial \theta}\left[\mu_{e f f}\left(\frac{1}{r} \frac{\partial \bar{w}}{\partial \theta}+\frac{2 \bar{v}}{r}\right)\right]\end{array}$ & $\frac{\partial\left(\frac{\bar{w}}{r}\right)}{\partial r}+\frac{1}{r} \frac{\partial \bar{v}}{\partial \theta}$ & $-\frac{\rho \bar{w} \bar{v}}{r}$ \\
\hline
\end{tabular}

Table (1):- variables of equations

THE K- $\varepsilon$ TURBULENCE MODEL:-

Jones and Launder had proposed the following equations for both the turbulence kinetic energy $(\mathrm{k})$ and for energy dissipation $(\varepsilon)[10]$

For turbulence kinetic energy $(\mathrm{k})$

$\rho \bar{u} \frac{\partial k}{\partial z}+\rho \bar{v} \frac{\partial k}{\partial r}+\rho \bar{w} \frac{\partial k}{\partial \theta}=\frac{\partial}{\partial z}\left(\frac{\mu_{t}}{\sigma_{k, t}} \frac{\partial k}{\partial z}\right)+\frac{1}{r} \frac{\partial}{\partial r}\left(\frac{\mu_{t}}{\sigma_{k, t}} r \frac{\partial k}{\partial r}\right)+\frac{1}{r} \frac{\partial}{\partial \theta}\left(\frac{\mu_{t}}{\sigma_{k, t}} \frac{\partial k}{\partial \theta}\right)-\rho \varepsilon+\mu_{t} G$

For energy dissipation rate $(\varepsilon)$

$\rho \bar{u} \frac{\partial \varepsilon}{\partial z}+\rho \bar{v} \frac{\partial \varepsilon}{\partial r}+\rho \bar{w} \frac{\partial \varepsilon}{\partial \theta}=\frac{\partial}{\partial z}\left(\frac{\mu_{t}}{\sigma_{\varepsilon, t}} \frac{\partial \varepsilon}{\partial z}\right)+\frac{1}{r} \frac{\partial}{\partial r}\left(\frac{\mu_{t}}{\sigma_{\varepsilon, t}} r \frac{\partial \varepsilon}{\partial r}\right)+\frac{1}{r} \frac{\partial}{\partial r}\left(\frac{\mu_{t}}{\sigma_{\varepsilon, t}} \frac{\partial \varepsilon}{\partial \theta}\right)+C_{1} \frac{\varepsilon}{k} \mu_{t} G-C_{2} \frac{\varepsilon^{2}}{k}$

Where $\mathrm{G}$ refers to the generation term and is given by [37]:

$G=2\left[\left(\frac{\partial \bar{u}}{\partial z}\right)^{2}+\left(\frac{\partial \bar{v}}{\partial r}\right)^{2}+\left(\frac{\bar{v}}{r}\right)^{2}\right]+\left[\left(\frac{\partial \bar{u}}{\partial r}\right)+\left(\frac{\partial \bar{v}}{\partial z}\right)\right]^{2}+\left(\frac{\partial \bar{w}}{\partial z}\right)^{2}+\left(\frac{\partial \bar{w}}{\partial r}-\frac{\bar{w}}{r}\right)^{2}$

The turbulent kinetic energy $(\mathrm{k})$ and the dissipation rate of the turbulent energy $(\varepsilon)$ are chosen as the two properties in order to determine the turbulent viscosity $\mu \mathrm{t}$

$\cdot \mu_{t}=\frac{C_{\mu} \rho k^{\frac{1}{2}}}{l^{-1}}$ 
Where: $\mathrm{C} \mu$ is a constant. It is assumed that at a high Reynolds number, $(\varepsilon)$ value to be Proportional to $k^{\frac{3}{2}} / l$, the above equation becomes:-

$\mu_{t}=\frac{C_{\mu} \rho k^{2}}{\varepsilon}$

The quantities $\sigma \mathrm{k}, \mathrm{t}, \mathrm{C} 1, \mathrm{C} 2, \sigma \varepsilon, \mathrm{t}$ and $\mathrm{C} \mu$ that appear in the $\mathrm{k}-\varepsilon$ model and $\mu$ equations, are the universal $\mathrm{k}-\varepsilon$ model constants, whose values are reproduced in table (2) .

Table (2):-shows the variable of $\mathrm{k}-\varepsilon$ model.

\begin{tabular}{|l|l|l|l|l|l|}
\hline Equation & $\Phi$ & $\Gamma_{\Phi}$ & $S_{\Phi}$ & $C_{\boldsymbol{I}}$ & 1.44 \\
\hline Turbulent K.E.eq. (12) & $\boldsymbol{K}$ & $\boldsymbol{\mu}_{\boldsymbol{t}} / \sigma_{k, t}$ & $-\rho \varepsilon+\mu_{t} G$ & $\boldsymbol{C}_{2}$ & 1.92 \\
\hline Dissipation rate eq.(13) & $\boldsymbol{\varepsilon}$ & $\boldsymbol{\mu}_{\boldsymbol{t}} / \sigma_{\varepsilon, t}$ & \multirow{2}{*}{$\mu_{t} G C_{1} \frac{\varepsilon}{k}-C_{2} \frac{\varepsilon^{2}}{k}$} & $\boldsymbol{C}_{\boldsymbol{\mu}}$ & 0.09 \\
\cline { 4 - 6 } & & & $\sigma_{k, t}$ & 1 \\
\cline { 4 - 6 } & & & $\sigma_{\varepsilon, t}$ & 1.3 \\
\hline
\end{tabular}

The CFD modeling of mixing problem, consist of three steps which are pre-processing, equation solving and postprocessing. In first part the problem geometry should be built and meshed. In the second step the partial differential equations describing the flow (Continuity and Navier-Stokes) are discretized on the mesh and solved simultaneously. The boundary and initial conditions should be introduced to the CFD. The turbulence model selected which is describing the effect of turbulence on the bulk flow properties of the fluid. Finally, the obtained results should be analyzed.

\section{The Numerical Solution Setup:-}

In the present study, mixing in 21.2 liter of water agitated by Retreat impellers. The mixing tank model mesh type is tetrahedron and it divided in to58244 nodes as shown in figure 3. The MFR method was applied for modeling the impeller rotation. Also the continuity and Navier-Stokes equations together with the RNG version of the K-E were used to describe the equation of motion.

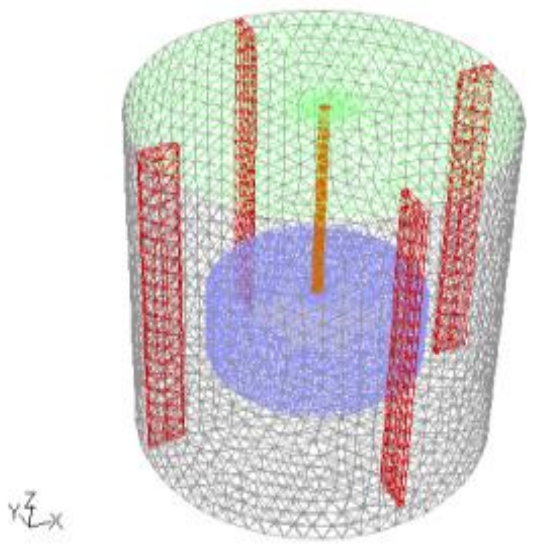

Figure 3:- Mixing Tank Modeling and Mesh Geometry.

\section{Results and Discussions:-}

The impeller rotation speed has a great effect on fluid motion in mixing processes. Consequently, the efficiency of settling process for the solid material is affected by the changing of impeller rotation speed. Also, the concentration of chemical additives would become more homogeneous when the optimum impeller rotation speed has been correctly selected.

Figuer.4 illustrates the velocity vectors and contours for Z- $\theta$ planes for Retreat impeller rotates at $90 \mathrm{rpm}$. For plane at $\theta=0^{\circ}$, the impeller blades pumped the fluid radially toward tank wall that cause fluid to split into two jets. The small jet is circulated downward to the bottom of tank and then returns to the impeller zone so produces an eddy in 
the zone below the impeller. The center of eddy is located at radius of $0.113 \mathrm{~m}$ from the tank center and $0.061 \mathrm{~m}$ from the bottom of tank. A Poor or weak mixing region is exists at the center of tank below the impeller.

The second jet of the fluid will be circulated in upward direction, so generates an eddy which is located at same radial direction with lower one but with height of $0.138 \mathrm{~m}$ from the bottom of the tank. The flow pattern will be same at $30^{\circ}$ and $60^{\circ}$ planexcept the reduction in the fluid flow velocity at the upper zone especially at $30^{\circ}$ planand velocity of fluid near the wall of tank increases in the upward direction. The fluid flow behavior in $90^{\circ}$ plan is similar to that observed at $0^{\circ}$ plan.

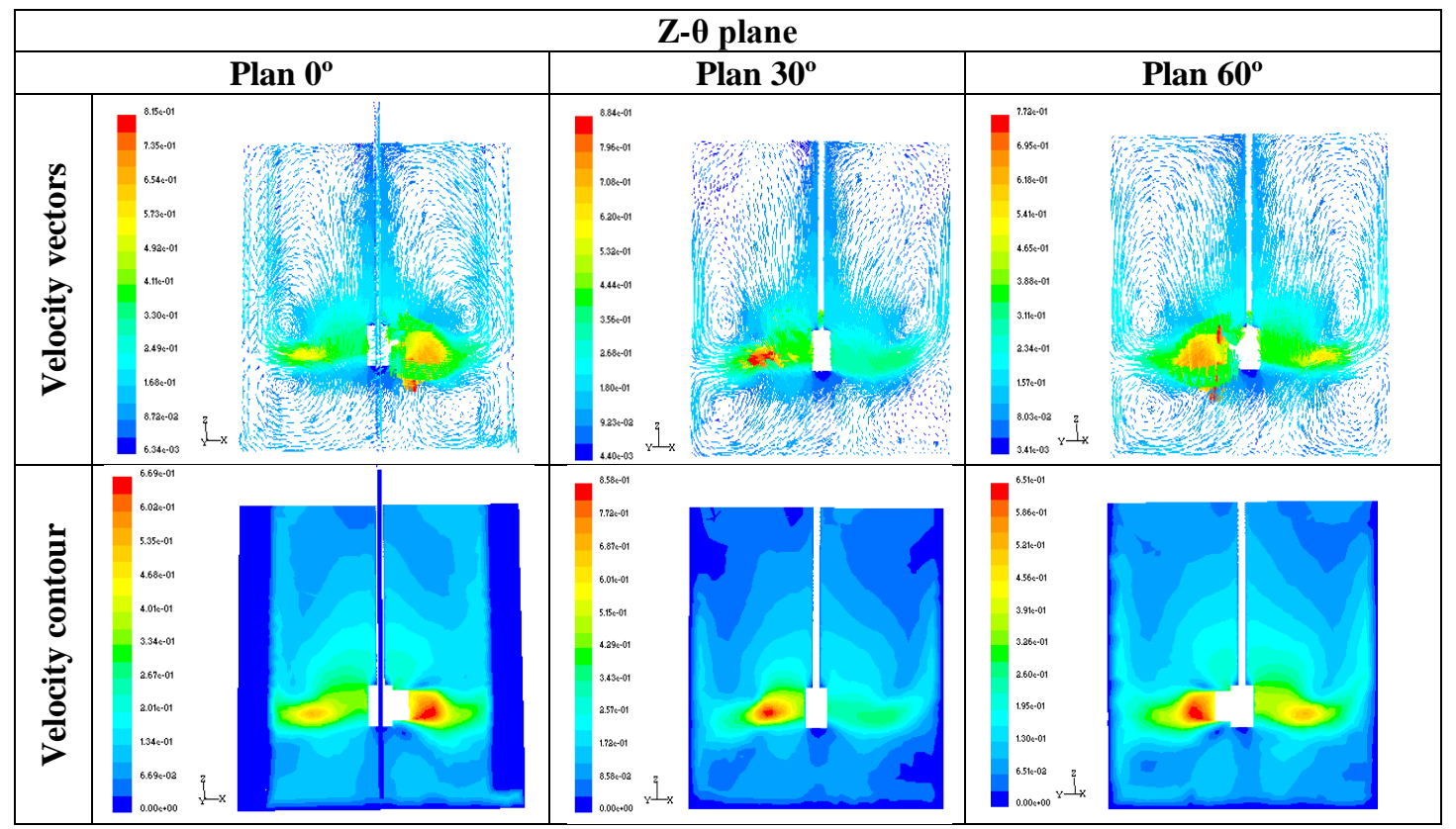

Figure 4:- Velocity Vectors and Contour for retreat Impeller Rotate at $90 \mathrm{Rpm}$.

Figuer.5 showed the velocity vectors and contours In Z-R direction at height $0.01 \mathrm{~m}$ velocity vectors and contour shows the poor mixing zone in the center of tank. The velocity increases toward the wall of tank, and then the velocity decreases near the tank wall, this fluctuation of velocity lead to form zones with high mixing. At height of $0.1 \mathrm{~m}$ (impeller zone) the velocity linearly increases along the blade of impeller until it reaches to its maximum value at the tip of the blade. Then the velocity is sharply decreases as a result of the pumping direction. At the free surface of fluid the velocity decreases because most of the fluid circulates in the lower zone due to the influences of impeller pumping capacity. The high mixing zone reduces especially at the center of tank but swirling motion continues near the baffles wall. 


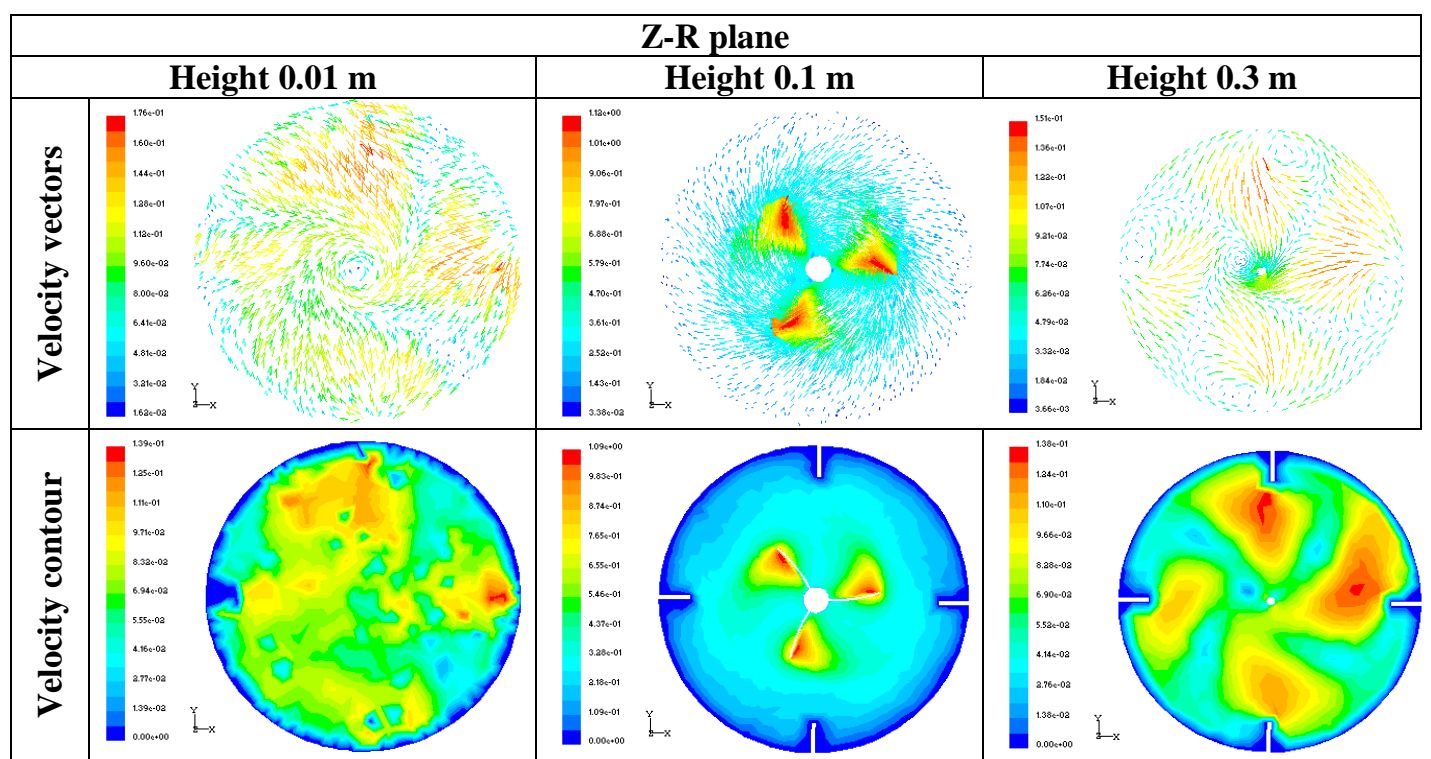

Figure 5:- Velocity Vectors and Contour for Retreat Impeller Rotate at $90 \mathrm{Rpm}$

Figure 6 showed the velocity vectors and contours in the Z- $\theta$ plan and Z-R plan at impeller rotational speed 135 rpm. It can observe that there are no significant changes on the fluid behavior or on the flow pattern. But the velocity magnitude increases as the impeller rotation speed increases.

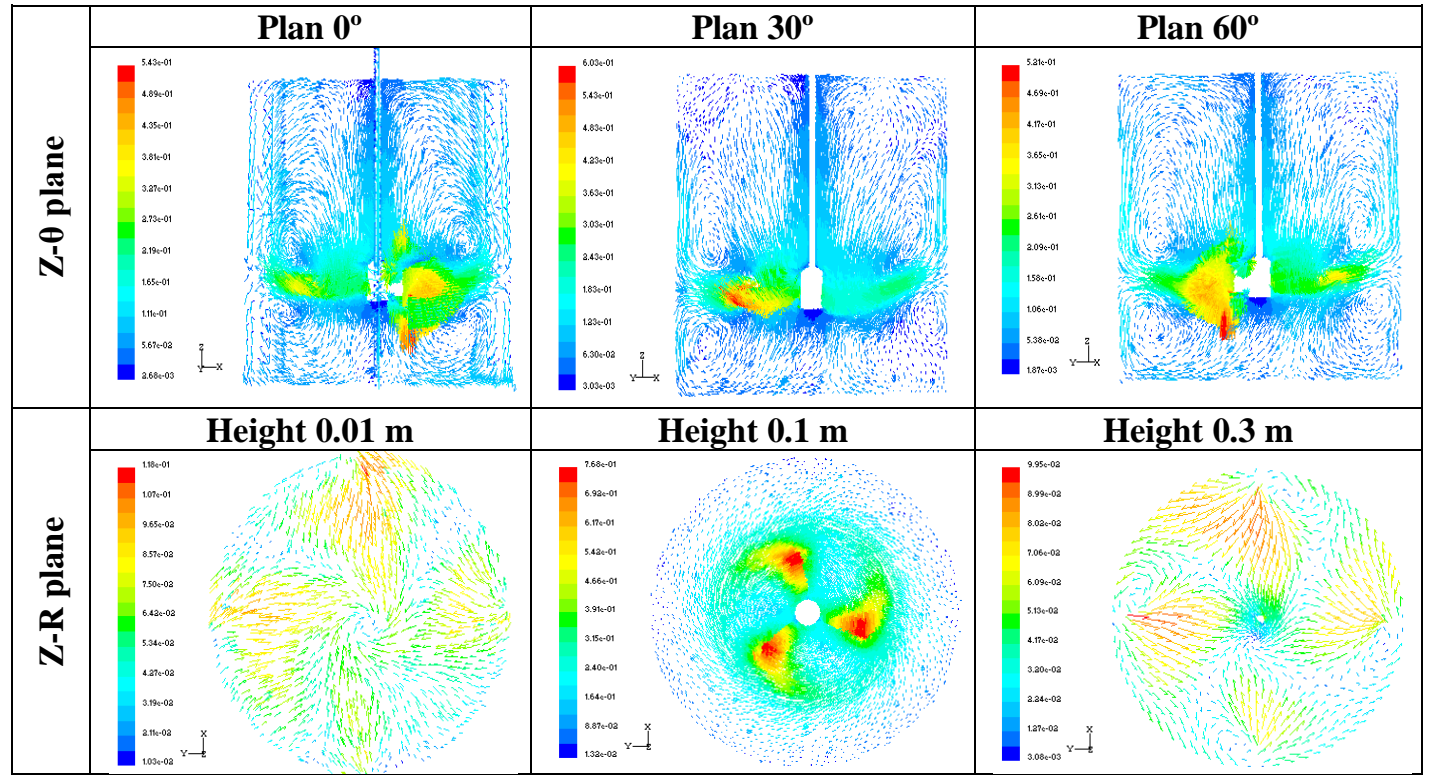

Figure 6:-Velocity Vectors for Retreat Impeller Rotate at 135 rpm

Figures (7-9) illustrates the velocity magnitude distribution with respect to tank radius in Z-R plan with various impeller rotational speeds. It can observe that the velocity fluctuations are not sufficient at low rotational speed and it becomes more sufficient at $90 \mathrm{rpm}$ and the velocity fluctuated increased as rotational speed of impeller increased. This occurs at three difference levels $(0.1,0.1$, and 0.3$) \mathrm{m}$ in mixing tank. The same thing occurs with velocity distribution at $\mathrm{R}-\theta$ plan $\left(0^{\circ}, 30^{\circ}\right.$ and $\left.60^{\circ}\right)$ as shown in figures (10-12) 


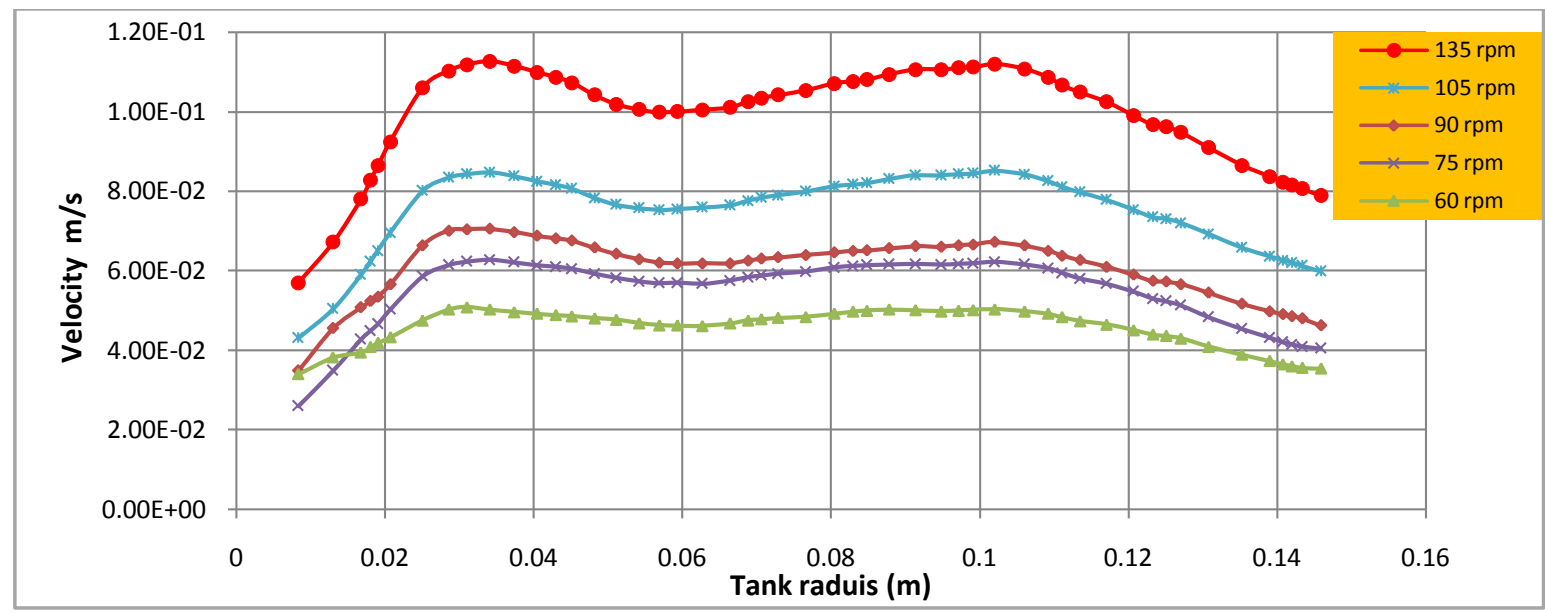

Figure 7:- Velocity Distribution for Retreat Impeller Z-R plan and Height $0.01 \mathrm{~m}$

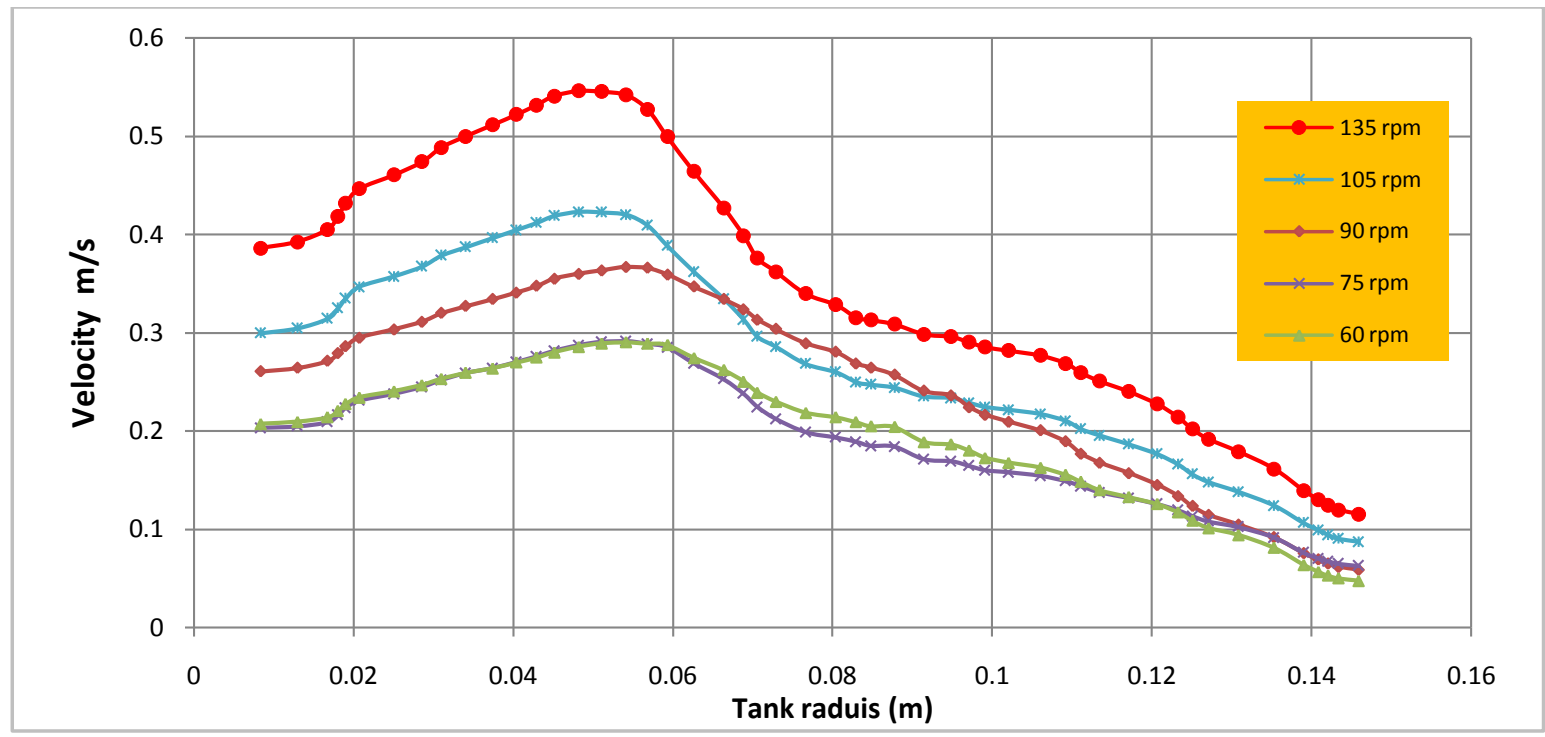

Figure 8:-Velocity Distribution for Retreat Impeller Z-R plan and Height $0.1 \mathrm{~m}$

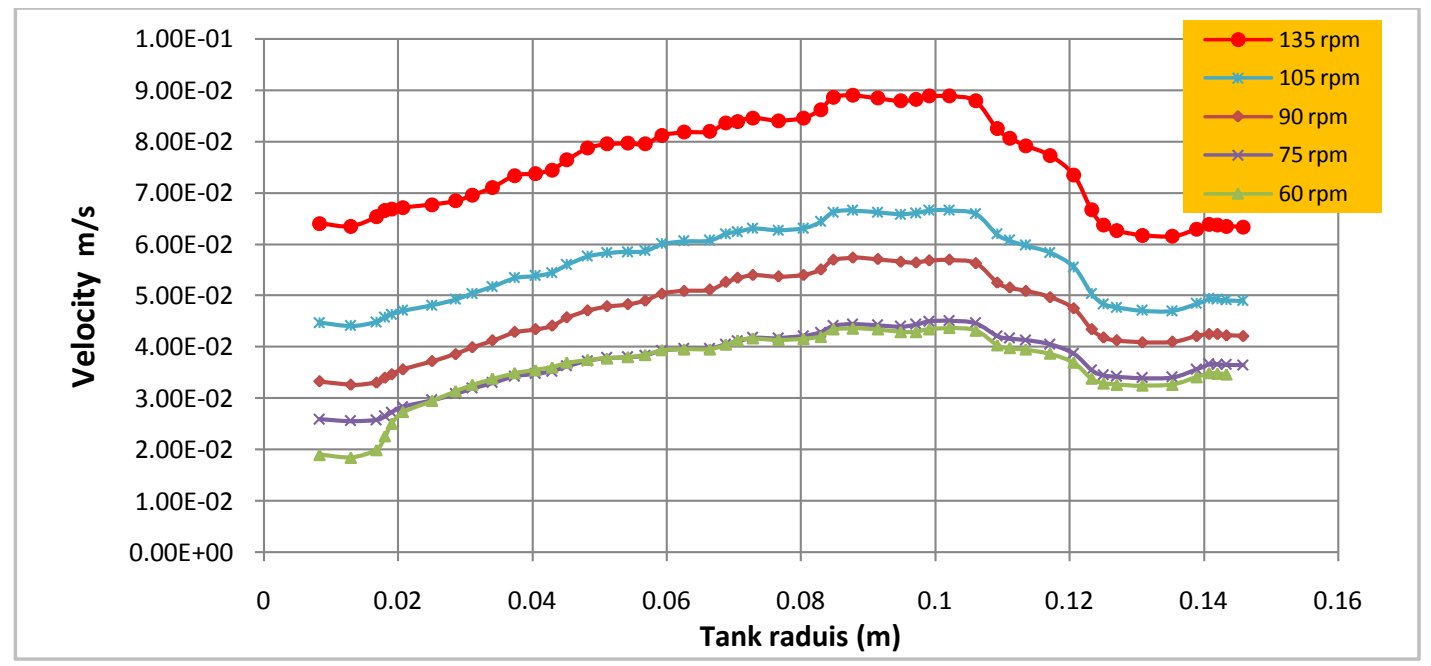

Figure 9:-Velocity Distribution for Retreat Impeller Z-R plan and Height $0.3 \mathrm{~m}$ 


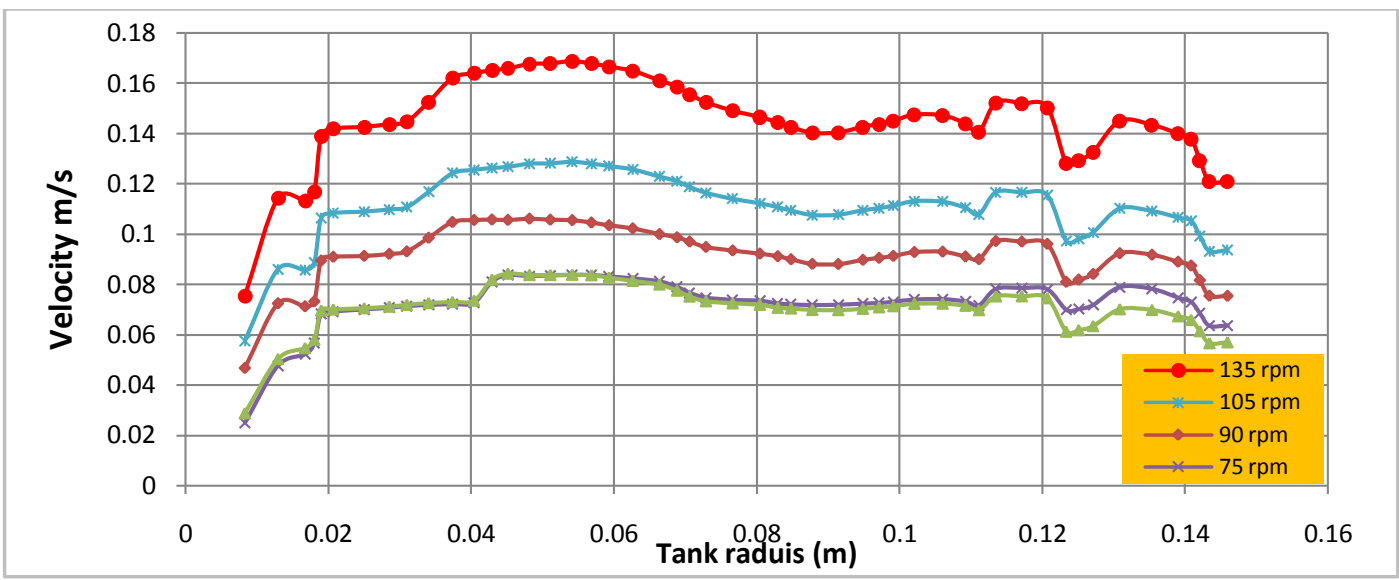

Figure 10: Velocity Distribution for Retreat Impeller at Z- $\theta$ plan $0^{\circ}$

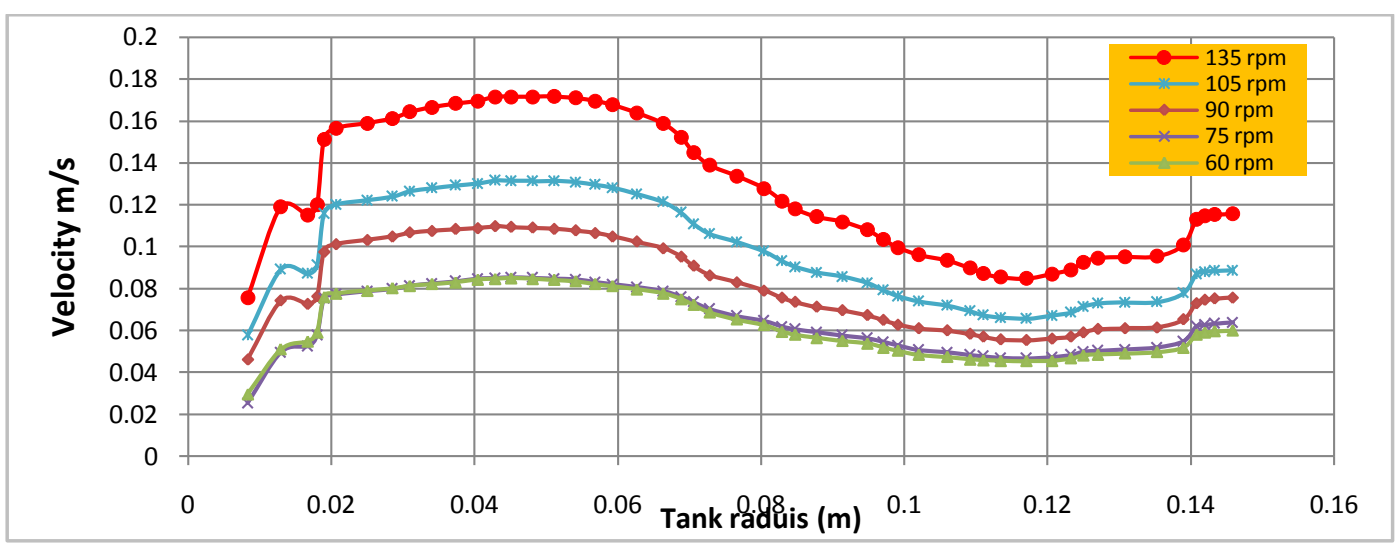

Figure 11:- Velocity Distribution for Retreat Impeller at Z- $\theta$ plan $30^{\circ}$

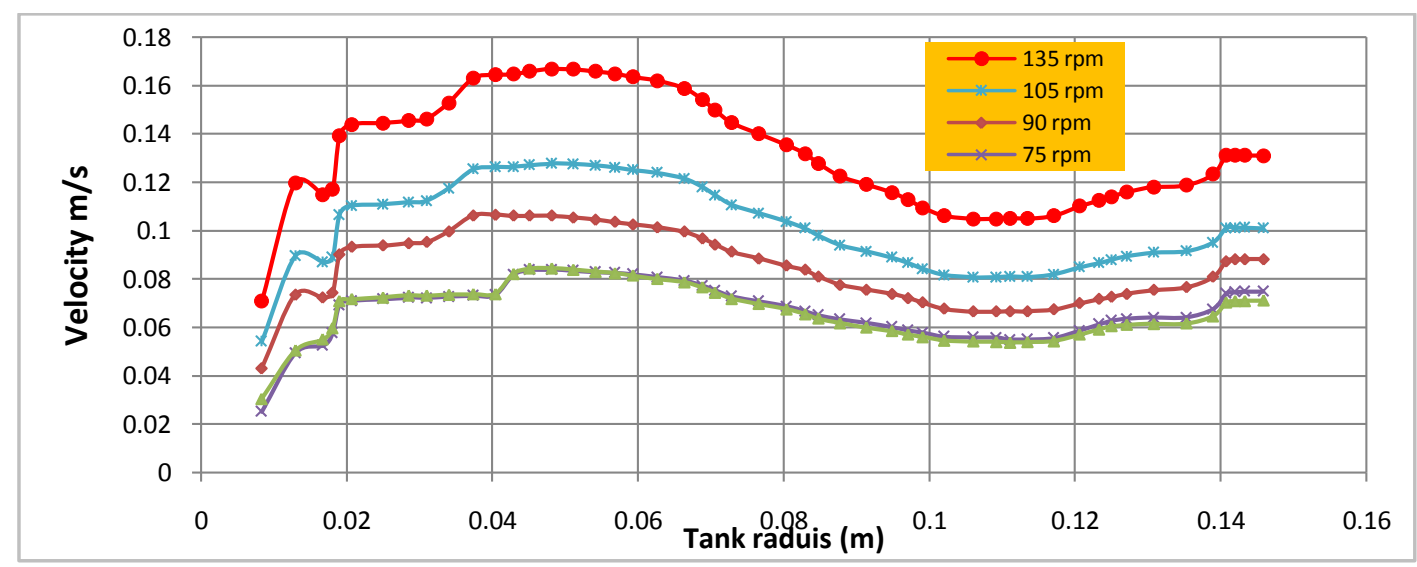

Figure 12:-Velocity Distribution for Retreat Impeller at Z- $\theta$ plan $60^{\circ}$

\section{Conclusion:-}

The FLUENT v.15.4 is used to analysis the Retreat impeller used for mixing purpose in cylindrical mixing tank. The following conclusions and the results of the study:

1. The numerical analysis gives good results of velocity distribution and mixing rate with the tank. Such results can be used for describing the flow behaviour.

2. Velocity vectors show that the poor mixing zones are generated in the mixing tank.

3. The velocity fluctuation of the fluid increases as rotational speed increased. 


\section{References:-}

1. Wei-Ming Lu, Hong-Zhang Wu and Ming-Ying Ju, " Effect of Baffle design on the Liquid Mixing in an Aerated Stirred Tank with Standard Rushton Turbine Impeller", Pergamon, Chemical Engineering Science , vol.52, No.21:22, pp.843-3851, 1997.

2. Joel J. Ducoste, Mark M. Clark, "Turbulence in Flocculators: Comparison of Measurements and CFD Simulations" AIChE. Journal, vol.45, No.45, pp.432-436, February, 1999.

3. Masoud Rahimi, "The Effect of Impellers Layout on Mixing in a Large-Scale Crude Oil Storage Tank" Elsevier, Journal of Petroleum Science \& Engineering, vol. 46, pp.161-170, 2005.

4. Aoyi Ochieng, Maurice S. Onyango, Anil Kumar, Kirimi Kiriamiti, Paul Musonge "Mixing in a Tank Stirred by a Rushton turbine at Low Clearance", Elsevier, Chemical Engineering and Processing, vol.47, pp.842-851, 2008.

5. Angelique Delafosse, Alain Line, Jerome Morchain and Pascal Guiraud, "LES and URANS Simulation of Hydrodynamics in Mixing Tank: Comparison to PIV Experiments", Elsevier, Chemical engineering Research and Design, vol.86, pp.1322-1330, 2008.

6. R. Zadghaffari, J. S. Moghaddas, M. Ahmadlouydarab, J. Revstedt "A Mixing Study in a Double-Rushton Stirred Tank", Fourth International Conference on Advanced COmputational Methods in ENgineering (ACOMEN), University of Liège, Belgium, 26-28 may, 2008.

7. H. Ameur and M. Bouzit, "Mixing in Shear Thinning Fluids", Brazilian Journal of Chemical Engineering, vol.29, No.2, pp. 349-358, April-June 2012.

8. M. Ammar, Z. Driss, W. Chtourou, M. S. Abid, "Effect of The Tank Design on The Flow Pattern Generated with Pitched Blade Turbine", International Journal of Mechanics and Applications, vol.2, No.1, pp.12-19, 2012.

9. Sharma Alok, Genitha Immanuel, "Effect of Different Impellers and Baffles on Aerobic Stirred Tank Ferment Using Computational Fluid Dynamics", Journal of Bioprocessing and Biotechniques, vol.4, issue 7, 2014.

10. J. Arturo Alfaro-Ayala, Victor Ayala-Ramirez, Armando Gallegos-Munoz, Agustin R. Uribe-Ramirez, "Optimal Location of Axial Impeller in a Stirred Tank Applying Evolutionary Programing and CFD", Elsevier, Chemical Engineering Research and Design, vol.100, pp.203-211, 2015.

11. W. Nienow, D. Miles "The Effect of Impeller / Tank Configuration on Fluid-Particle Mass Transfer" Elsevier Sequoia, The Chemical Engineering Journal, vol.15, pp.13-24, 1978.

12. Georgy T. , Franklin, L. Burton " Wastewater Engineering, Treatment, Disposal, And Result " . McGraw-Hill series in water resources and environmental engineering, 3rd edi. , 1991 . PP: 217.

13. ANSYS Fluent, http://www.ansys.com/Industries/Acaemic/Tools/Citations.

14. Yakhot, V., and Orszag, S. A., I. Basic Theory. J. Scientific Computing, 1986.

15. E. Pulat, M. Kemal, I. A. B. Etemoglu, M. Can, Numerical Heat Transfer, Part B 2011, 60, 486.

16. B. E. Launder, D. B. Spalding, Lectures in Mathematical Models of Turbulence, Academic Press, London, 1972.

\section{Nomenclature}

\begin{tabular}{|c|c|c|}
\hline Symbols & Description & SI Unit \\
\hline $\mathrm{a}$ & Acceleration & $\mathrm{m} / \mathrm{s}^{2}$ \\
\hline $\mathrm{C}_{0}$ & Constant & \\
\hline $\mathrm{C}_{1}$ & Constant & \\
\hline $\mathrm{C}_{2}$ & Constant & \\
\hline $\mathrm{C}_{\mu}$ & Constant & \\
\hline $\mathrm{D}_{\mathrm{i}}$ & Impeller diameter & $\mathrm{m}$ \\
\hline$D_{t}$ & Diameter of mixing tank & $\mathrm{m}$ \\
\hline $\mathrm{E}_{\mathrm{k}}$ & Turbulent kinetic energy in equation (3-52) & $\mathrm{m}^{2} / \mathrm{s}^{2}$ \\
\hline $\mathrm{C}$ & Impeller clearance & $\mathrm{m}$ \\
\hline $\mathrm{H}$ & Liquid height in mixing tank & $\mathrm{m}$ \\
\hline$N$ & Impeller rotation speed & $\mathrm{rev} / \mathrm{min}$ \\
\hline $\mathrm{p}$ & Pressure & $\mathrm{N} / \mathrm{m}^{2}$ \\
\hline $\mathrm{r}$ & Radius of mixing tank & $\mathrm{m}$ \\
\hline $\mathrm{S}_{\mathrm{r}}$ & Source term in r-direction of momentum equation & \\
\hline$S_{\theta}$ & Source term in $\theta$-direction of momentum equation & \\
\hline$S_{k}$ & Source term in k- $\varepsilon$ model & \\
\hline $\mathrm{S}_{\varepsilon}$ & Source term in $k-\varepsilon$ model & \\
\hline
\end{tabular}




\begin{tabular}{|l|l|l|}
\hline $\mathrm{t}$ & Mixing time & $\mathrm{s}$ \\
\hline$U$ & Velocity vector in z - direction & $\mathrm{m} / \mathrm{s}$ \\
\hline$u$ & Velocity in z-direction & $\mathrm{m} / \mathrm{s}$ \\
\hline$V$ & Velocity vector in $\theta$ - direction & $\mathrm{m} / \mathrm{s}$ \\
\hline$v$ & Velocity in r-direction & $\mathrm{m} / \mathrm{s}$ \\
\hline$W$ & Velocity vector & $\mathrm{m} / \mathrm{s}$ \\
\hline$w$ & Velocity in $\theta-$ direction & $\mathrm{m} / \mathrm{s}$ \\
\hline$\rho$ & Density & $\mathrm{kg} / \mathrm{m} 3$ \\
\hline$\varepsilon$ & Dissipation rate of kinetic turbulence energy & $\mathrm{m} 2 / \mathrm{s} 3$ \\
\hline$\varepsilon w$ & Dissipation rate of kinetic turbulence energy at wall & $\mathrm{m} 2 / \mathrm{s} 3$ \\
\hline$\varepsilon e$ & Eddy viscosity & $P a . s$ \\
\hline$\Gamma$ & Arbitrary parameter & \\
\hline
\end{tabular}

